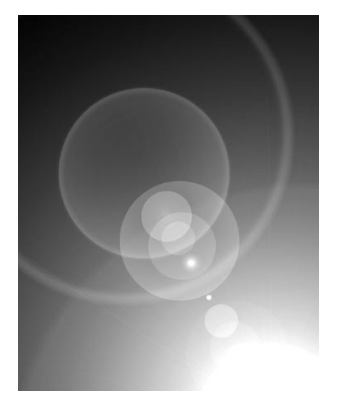

\title{
Ethics in quasi-experimental research on people with severe learning disabilities: dilemmas and compromises
}

\begin{abstract}
Mary Kellett School of Education, Oxford Brookes University, Wheatley Campus, Oxford OX33 1HX, UK; Melanie Nind School of Education, The Open University, Walton Hall, Milton Keynes MK7 6AA, UK
\end{abstract}

\section{Summary}

\begin{abstract}
The present paper follows up the theme of research ethics that has been discussed in the British Journal of Learning Disabilities in recent years. We join the debate in the capacity of people involved in doing research on, rather than with, people with learning disabilities. We focus on our own quasi-experimental study evaluating the Intensive Interaction approach for pupils who are preverbal. We question our own practice, and illustrate some of the dilemmas which we have faced in our research and some of the compromises which we have reached.
\end{abstract}

Keywords Consent, ethics, intensive interaction, research design, severe learning disabilities

\section{Introduction}

The 1998 British Journal of Learning Disabilities special issue on the theme of research ethics illustrated how debates about research ethics are shifting in the current climate which focuses on inclusion and human rights. The question of how people with learning disabilities can be meaningfully involved in research continues to be topical, particularly for researchers working with qualitative approaches. Kiernan (1999) reviewed the recent relevant literature and the present authors will not repeat this work. However, we do acknowledge the fine examples of research projects which have attempted to empower people with learning disabilities and give them a voice (e.g. Ward \& Simons 1998). Oral history approaches (in which people tell their stories in their own words) and participatory action research (in which people identify problems and act together to bring about change) are well suited to addressing the power imbalances between people with learning disabilities and those who have traditionally 'researched them'.

The present paper responds to the call for papers addressing ethics in other kinds of research. Quasi-experimental research involves different assumptions from qualitative research. It is less concerned with multiple truths and more concerned with testing hypotheses. As experimental researchers, the current climate can make us feel somewhat uncomfortable and certainly vulnerable. With the rights and voices of people with learning disabilities seen as so important, we could come to see ourselves as an anachronism. This leaves us with (at least) three options: (1) We change the type of research that we do and the type of questions which we ask. (2) We could give up and go home! Or (3) we could accept our vulnerability and limitations, and join the debate with honesty and an open mind. It is this last option that we are interested in exploring.

In the present paper, we use the example of our own ongoing quasi-experimental research to explore the ethical issues which arise and how we might respond to these in ways which are appropriate for our values position as well our research design. We also explore the issues of research involving individuals who are preverbal and who have profound intellectual impairments. This is timely because the concept of people with learning disabilities as partners in research brings with it the danger of omission in research of those with the greatest disabilities. These individuals may be left outside research efforts because they are perceived as too difficult to include. We do not think that some people with (learning) disabilities can effectively represent all people 
with learning disabilities, including those who are profoundly intellectually impaired, but we do not yet have models for involving people with profound learning disabilities as real partners in research. This leaves us with the (non)option of being tokenistic or with a dilemma. Do we compromise with whom we do our research or do we compromise the ideal of dialogue in our methods?

Our research is an evaluation of Intensive Interaction (Nind \& Hewett 1994). In Kiernan's (1999, p. 43) terms, this is 'research on rather than research with' people with learning disabilities. A central aim of the present study was to identify what happened to the social and communicative abilities of six young children when Intensive Interaction was used. The first matter of ethical debate is whether the research is worth doing and whose interests are served by it. There has been a call for research that pursues the agenda of people with (learning) disabilities themselves, rather than research pursuing the agenda of non-disabled academics (Morris 1992; Oliver 1992; Barnes \& Mercer 1997). For people with profound intellectual impairment, this can be a double bind since research leading to enhanced lifestyles for this group may not be a priority on either agenda.

Intensive Interaction is an approach to enabling people with profound or complex learning disabilities to be more effective communicators, and those who work with and care for them to be more effective 'listeners'. It has evolved from analysis of the characteristics of the natural model of caregiver-infant interaction. A set of working principles, rather than any prescribed content, is employed in both everyday incidental interactions and regular quality sessions which are subjected to critical reflection. The intervention involves daily, recorded one-to-one interactions in which the teacher takes the learner's lead, responds contingently to the learner's behaviours, and treats them as if they have social or communicative intent. The teacher's interpersonal behaviours are modified, and sensitive use is made of timing, rhythm, playfulness, watching, waiting and adapting based on non-verbal feedback. The approach itself could be subjected to ethical scrutiny, particularly considering its element of offering developmentally appropriate interactions, sometimes in the face of chronological age, which has been passionately debated (Nind \& Hewett 1996; Smith 1996; Samuel \& Maggs 1998).

Intensive Interaction is concerned with the interactive processes that occur and is not bound up with a medical model. Therefore, evaluative research that furthers professionals' and families' understandings of the efficacy of the approach clearly stands to benefit people with profound learning disabilities by reducing the barriers to their effective communication. Indeed, although this research may not be emancipatory or empowering in the ways often currently called for (Kitchen 2000), it does seek to both change the views of the wider society and enable change of the individuals involved.
Checking ourselves in the way that Barton (1998, p. 34) modelled does not make us too uncomfortable in terms of: Who is this work for? What right do we have to undertake it? and What responsibilities come with it? We do not doubt that we, the academics, and other professionals will benefit from the research, but this is in addition to people with learning disabilities and their families, and not at their expense.

The present evaluation of Intensive Interaction with children is a replication/adaptation of an earlier study with adults in a long-stay hospital (Nind 1996). The replication element limited the choice of research design, but with a new researcher leading the project, new ethical questions were asked of the methods, and the design and tools were put under new scrutiny.

\section{Quasi-experimental research design}

We encountered many ethical (and practical) dilemmas when we embarked on this project, not least in the research design itself. A means of evaluating the effectiveness was needed and we did not have the option of pupils explaining how it was for them in their own words. An option was to measure progress in two groups, one getting Intensive Interaction and one not, in a 'control group' design. However, on a practical level, it is impossible to find a 'typical' or 'representative' group, and a satisfactory sample match (Hogg \& Sebba 1986). A pragmatic alternative would have been to use a 'reversal phase', with one group getting the intervention for a period before it was withdrawn to see if progress was halted or reversed.

Both the models present serious ethical concerns. Based on previous research (Nind 1996; Watson \& Fisher 1997), we hypothesized that Intensive Interaction would facilitate social and communication development. To withhold or withdraw something of benefit in order to prove its effectiveness would be unethical and potentially damaging to the welfare of the research participants.

To overcome these problems, we opted for a multiplebaseline interrupted time-series design (Cuvo 1978; Cook \& Campbell 1979; Nind 1996). This meant a series of assessments throughout a baseline and intervention phase (and the intervention continuing beyond the duration of the study). While participants began the baseline phase together, the start of the intervention was staggered. Thus, the approach was delayed for a few weeks rather than withheld or withdrawn. The design was strong in that a pattern of individuals making progress around their intervention start-times would indicate a relationship between progress and intervention. The most plausible explanation of outcomes would be that the intervention was responsible for change (Glass et al. 1975; Borg 1987). In effect, the participants would become their own controls, enabling a workable compromise to be reached between experimental rigour and ethical considerations. 


\section{Informed consent}

In collaboration with staff, six children from two primary special schools (severe learning disabilities) schools and one integrated nursery were selected for the present study. Before proceeding, the informed consent of the children, or at least, their parents/guardians was required. We took steps to give parents full and honest information, and to ensure that our consent was not pressured or coerced, but this did not fully discharge our ethical responsibilities. We were going to be working with preverbal children with severe learning disabilities aged between 4 and 11 years: How could we ensure that the subjects were participating with informed consent? While we could not construe the subjects as partners in research, we still had a duty to ensure that these individuals were comfortable with participation and we could not ascertain this through dialogue. Like Stalker (1998), we could find no precedents for this in the literature and we found that we had to devise our own framework.

Starting with the children as their focal point, we involved the network of people who understood the subjects, cared about them, and knew when they were unhappy, distressed or uncomfortable. We sought open dialogue with this network with the aim of being assured of the ongoing consenting status of the children. Such approaches to consent issues involve expanding traditional researcher-teacher-parent relationships to include other concerned individuals such as siblings, friends and support staff. We wanted to make real the notion of the participants' right to withdraw at any point. Like Knox et al. (2000), we saw consent in terms of an ongoing process involving a network of advocates who would allow for functional informed consent in a complex situation.

The effects of this were to make the researcher who gathered the observational data on a weekly or fortnightly basis much more involved in the lives of those involved with the project than she might otherwise have been. It was necessary to forge good relationships and trust such that open dialogue was made possible. Face-to-face contact, phone calls, home-school books and home visits were all used. In this way, not only did the successful implementation of the intervention rely on the interpersonal qualities of the practitioners, but the evaluation itself relied on the interpersonal qualities of the researcher. This perhaps blurred the boundaries between a quasi-experimental approach and more interpretative approaches. There was also compromise because the additional sharing and cooperation required in this model inevitably diluted the power and control of the researcher.

\section{Duration of baseline}

The intervention and design for evaluating it were known to have been effective with adults in a long-stay hospital (Nind
1996). However, the practical implementation of this design in a community special school raised some unforeseen issues. This concurs with the growing concern in recent years about ethical practice in special education research (Shakespeare 1996; Gray \& Denicolo 1998; Stalker 1998).

The design element of a staggered start to the intervention meant that one child in each school would start Intensive Interaction after 4 weeks, one after 8 weeks and one after 12 weeks. However, following Intensive Interaction training, the teachers were enthusiastic to begin. As they got going with other pupils, they became increasingly confident of the benefits of the approach and increasingly frustrated at the delay in its use with the research participants. At the design stage, a multiple baseline of 4,8 and 12 weeks seemed reasonable. In practice, it proved difficult for the first teacher to delay for 4 weeks, frustrating for the second teacher attempting to delay for 8 weeks and virtually impossible for the third teacher, who regarded 12 weeks as a whole term of lost opportunity.

This raises real dilemmas. From the researcher's perspective, multiple baselines avoid the need for a control group or reversal phase, while providing stronger evidence than a simple series of case studies. This allows for more comprehensive dissemination, and ultimately, wider benefits. From the teacher's perspective, the baseline period represents lost opportunities for progress. At what point does one choose between potentially greater benefits for greater numbers and probable benefits to an individual being delayed? Opting for the rigorous design still leaves the problem of the duration of the baseline phase. How long is long and how long is ethical? If 12 weeks is acceptable, but 20 weeks unacceptable, should the line be drawn at 12 weeks or at 19 weeks and 6 days? Who should make that judgement? The decision is likely to be a compromise, as it was for us, reached through dialogue between the researcher, steering group or supervisor, and the network of advocates called for earlier in the present paper. Following concern at the first 12-week baseline, the baselines in the second school were made 4,5 and 6 weeks long, rather than 4,8 and 12 weeks as planned.

\section{Measuring tools}

The present research also required a means of measuring social and communicative behaviour that could be used frequently, was non-intrusive and could show tiny changes. Several measures were needed for richness of data and triangulation (findings from different perspectives and means). Two published assessments, Kiernan \& Reid's (1987) Pre-Verbal Communication Schedule and an adaptation of Brazelton's (1984) Cuddliness Scale were used alongside systematic observation. This allowed for a more standardized and long-term view alongside the detail of social behaviour intricately coded second-by-second from 
video recordings. Participants were filmed initially weekly and then fortnightly over a period of one year.

Video data were analysed for: typical classroom behaviour when alone; any attempt to initiate social contact; responses to the proximity and physical contact of the teacher; interactive behaviour; and engagement in a one-to-one teacherpupil interactive session. Once again, the measures appeared reasonable, but as the pupils began to make progress, teachers and researcher felt increasingly uncomfortable with 'passive' situations where the teacher purposefully did not initiate interaction. Observation of positive responses to proximity and physical contact was originally sought as an early sign of progress. Nevertheless, these pupils seemed bewildered as to why teachers sometimes interacted intensively with them and sometimes passively.

Again, there was tension between rigorous method and contextual research ethics. For us, although such a rich source of experimentally valid data could strengthen the study, the potential distress to pupils was too high a price to pay. This inevitably lead to another compromise and a need to sacrifice some of the neat, tidy study in pursuit of rather messier but more ethical data. The passive condition for the assessment was abandoned for the first pupil-teacher pairing as soon as concern about its negative impact emerged. It was then dropped for the later pupils before concern emerged.

\section{Ownership of data}

A further issue arising from the project, but not necessarily linked to its experimental nature, concerned ownership of data. This project involved video recording of pupils and teachers in one-to-one social interactions. Who should own the data: the pupils, teachers, parents, researchers or funding source? Should ownership be shared jointly between all parties concerned? Or should the raw data be destroyed when analysis is complete so that these are not owned by anyone? The desire to extend just rights to participants may need to be tempered by logistical realism in order to protect data which could prove valuable in future studies. We were made to compromise again, and opted for a solution in which the researcher acted as 'banker' or unofficial archivist of the video data, storing it safely and enabling participants and their families to have their entitlement to view the material.

\section{Conclusion}

Conducting quasi-experimental research in current learning disability contexts raises many ethical dilemmas and exposes possible conflicts of interest between researchers and research participants. We fully recognize the limitations of any study in which the researcher has power and the researched are a separate vulnerable group, and we have shown how this power may be handled responsibly and perhaps shared. In experimental as well as interpretative research, there is potential power to do good, even to empower, as well as potential to do harm. Ethics committees and procedures should perhaps ask whether there are alternative designs in which the researched individuals can more actively become the researchers, but not rule out studies where this is not possible.

The growing number of groups involved in qualitative, participatory and emancipatory research may lead the way on research ethics in a new era, but they cannot be left to take the responsibilities which all researchers in the area of learning disabilities must share. The changing context of demands for inclusion, for evidence-based practice and for respect for all human rights should lead us to reflect on the practical benefits and ethical issues associated with our research. Having reflected on this study, we conclude that, like any research, it is not perfect, that all researchers need to seek compromises, and that dialogue is needed on purposeful ways forward.

\section{References}

Barnes C. \& Mercer C., editors (1997) Doing disability research. Leeds, Disability Press.

Barton L. (1998) Developing an emancipatory research agenda: possibilities and dilemmas. In: Clough P., Barton L., editors. Articulating with difficulty: research voices in inclusive education. London, Paul Chapman: 29-39.

Borg W.R. (1987) Applying educational research: a practical guide for teachers. New York, NY, Longman.

Brazelton T.B. (1984) Neonatal behavioural assessment scale. London, Heinemann Medical Books.

Cook T.D. \& Campbell D.T. (1979) Quasi-experimentation: design and analysis issues for field settings. Boston, MA, Houghton Mifflin.

Cuvo A.J. (1978) Multiple baseline in institutional research: pitfalls of measurement and procedural advantage. Am J Mental Deficiency, 84 (3): 219-28.

Glass G.V., Wison V.L. \& Gottman J.M. (1975) Design and analysis of time series experiments. Boulder, CO, Colorado Associated University Press.

Gray D.E. \& Denicolo P. (1998) Research in special needs education: objectivity or ideology? Br J Special Education, 25 (3): 140-5.

Hogg J. \& Sebba J. (1986) Profound retardation and multiple impairment, Vol. 1: Development and learning. London, Croom-Helm.

Kiernan C. (1999) Participation in research by people with learning disabilities: origins and issues. Br J Learning Disabilities, 27 (2): 43-7.

Kiernan C. \& Reid B. (1987) Pre-verbal communication schedule. Windsor, NFER-Nelson.

Kitchen R. (2000) The researched opinions on research: disabled people and disability research. Disability Soc, 15 (1): 25-47.

Knox M., Mok M. \& Parmenter T.R. (2000) Working with the experts: collaborative research with people with an intellectual disability. Disability Soc, 15 (1): 49-61. 
Morris J. (1992) Personal and political: a feminist perspective on researching physical disability. Disability, Handicap Soc, 7 (2): 157-66.

Nind M. (1996) Efficacy of Intensive Interaction: developing sociability and communication in people with severe and complex learning difficulties using an approach based on caregiver-infant interaction. European J Special Education Needs, 11 (1): 48-66.

Nind M. \& Hewett D. (1994) Access to communication: developing the basics of communication with people with severe learning difficulties through Intensive Interaction. London, David Fulton.

Nind M. \& Hewett D. (1996) When age-appropriateness isn't appropriate. In: Coupe O'Kane J., Goldbart J., editors. Whose choice? Contentious issues for those working with people with learning difficulties. London, David Fulton: 48-57.

Oliver M. (1992) Changes the social relations of research production. Disability, Handicap Soc, 7 (2): 101-14.

Samuel J. \& Maggs J. (1998) Introducing Intensive Interaction for people with profound learning disabilities living in small staffed houses in the community. In: Hewett D., Nind M., editors. Interaction in action: reflections on the use of Intensive Interaction. London, David Fulton: 119-148.

Shakespeare T. (1996) Rules of engagement: doing disability research. Disability Soc, 11 (1): 115-9.

Smith B. (1996) Discussion: Age-appropriate or developmentallyappropriate activities? In: Coupe O'Kane J., Goldbart J., editors. Whose choice? Contentious issues for those working with people with learning difficulties. London, David Fulton: 70-80.

Stalker K. (1998) Some ethical and methodological issues in research with people with learning difficulties. Disability Soc, 13 (1): 5-19.

Ward L. \& Simons K. (1998) Practising partnership: involving people with learning difficulties in research. Br J Learning Disabilities, 26 (4): 128-31.

Watson J. \& Fisher A. (1997) Evaluating the effectiveness of Intensive Interaction teaching with pupils with profound and complex learning difficulties. Br J Special Education, 24: 80-7. 